Acta Crystallographica Section D

Biological

Crystallography

ISSN 0907-4449

\title{
N-Acetyl-L-glutamate kinase from Escherichia coli: cloning of the gene, purification and crystallization of the recombinant enzyme and preliminary X-ray analysis of the free and ligand-bound forms
}

The gene for Escherichia coli $N$-acetyl-L-glutamate kinase (NAGK) was cloned in a plasmid and expressed in E. coli, allowing enzyme purification in three steps. NAGK exhibits high specific activity $\left(1.1 \mu \mathrm{mol} \mathrm{s}^{-1} \mathrm{mg}^{-1}\right)$, lacks Met1 and forms dimers (shown by crosslinking). Crystals of unliganded NAGK diffract to $2 \AA$ and belong to space group $P 6_{1} 22$ or its enantiomorph $P 6_{5} 22$ (unit-cell parameters $a=b=78.6, c=278.0 \AA$ ) with two monomers in the asymmetric unit. Crystals of NAGK with acetylglutamate and the ATP analogue AMPPNP diffract to $1.8 \AA$ and belong to space group $C 222_{1}$ (unit-cell parameters $a=60.0, b=71.9, c=107.4 \AA$ ), with one monomer in the asymmetric unit. NAGK crystallization will allow the determination of proposed structural similarities to carbamate kinase.
Received 15 March 1999

Accepted 19 April 1999

anstituto de Biomedicina de Valencia (CSIC), C/Jaime Roig 11, 46010-Valencia, Spain, and bIBMB-CSIC, Barcelona, Spain

\section{Introduction}

$\mathrm{N}$-Acetyl-L-glutamate kinase (NAGK; E.C. 2.7.2.8) phosphorylates the $\gamma$-COOH group of $\mathrm{N}$-acetyl-L-glutamate (NAG) in the second step of microbial arginine biosynthesis (Cunin et al., 1986). In many microorganisms NAGK is a crucial control point, being feedback-inhibited by the final product arginine (Cunin et al., 1986). Little is known about the structure and catalytic mechanism of NAGK. The $P$. aeruginosa enzyme is a homodimer of $29 \mathrm{kDa}$ subunits and appears to also form higher oligomers (Haas \& Leisinger, 1975). The genededuced amino-acid sequences indicate that bacterial and chloroplast NAGK polypeptides (Marina et al., 1998) are composed of 258-304 amino-acid residues and exhibit considerable sequence identity. Substantial sequence similarity (approximately 20\% identity and 40\% conservative replacement) was also found with carbamate kinase (Marina et al., 1998), the final enzyme of the arginine deiminase pathway of arginine catabolism and an enzyme whose three-dimensional structure we have recently determined (Marina et al., 1999). Carbamate kinase is a homodimer of polypeptides of approximately $30 \mathrm{kDa}$ and, similarly to NAGK, catalyzes the transfer of the $\gamma$-phosphoryl group of ATP to a $\mathrm{COO}^{-}$group. These similarities suggest that carbamate kinase and NAGK are structurally and functionally similar (Marina et al., 1999). Since carbamate kinase presents a new $\alpha / \beta$ fold, NAGK and carbamate kinase might be members of a new structural family which may also include, given the sequence similarities (data not shown), $\gamma$-glutamyl kinase and long-chain fatty acyl CoA synthetase. The present report is a necessary preliminary step in testing this possibility.

\section{Experimental}

The NAGK gene was PCR-amplified from $E$. coli DNA, using Deep Vent DNA polymerase (from New England Biolabs) and the primers 5'-CTTATTTACTAGTGTCATGATGAATC-

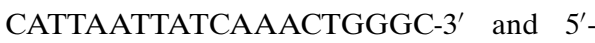
GCTGCGCCGCTCAGCAACAAAACTTAAGCTAAAATCCGC-3', which introduce $B s p \mathrm{HI}$ and $B l p \mathrm{I}$ sites at the initiator ATG and downstream of the stop codon, respectively. The BspHI- and BlpI-digested amplified fragment was ligated using T4 ligase into the $N c o$ I and BlpI sites of plasmid pET-15b (Novagen) and $E$. coli $\mathrm{DH} 5 \alpha$ cells (from Clontech) were transformed. Plasmid pNAGK24 was isolated and was shown by restriction analysis and automated DNA sequencing to harbour the full $N A G K$ gene. E. coli BL21(DE3) cells (from Novagen) transformed with pNAGK24 and grown to $A_{600}=0.6$ at $310 \mathrm{~K}$ in $1.51 \mathrm{LB}$ broth with $75 \mu \mathrm{g} \mathrm{ml}^{-1}$ ampicillin were induced for $3 \mathrm{~h}$ with $1 \mathrm{~m} M$ isopropyl- $\beta$-D-thiogalactoside and were harvested by centrifugation. Subsequent steps were carried out at $277 \mathrm{~K}$. The cells, suspended as $10 \mathrm{ml} \mathrm{g}^{-1}$ cells in $0.1 \mathrm{M}$ sodium phosphate $\mathrm{pH} 7.0,0.2 \mathrm{~m} M$ dithioerythritol, were disrupted by sonication. After centrifugation (30 min, 35000g), the protein in the supernatant which precipitated between 40 and $60 \%$ saturation (at $273 \mathrm{~K}$ ) of ammonium sulfate was dissolved in $20 \mathrm{ml}$ of buffer $A$ (10 $\mathrm{m} M$ sodium phosphate $\mathrm{pH}$ 7.0, $0.2 \mathrm{mM}$ dithioerythritol) and dialyzed against the same buffer before application to a Q-Sepharose 
Fast Flow (Pharmacia Biotech) column $(1 \times$ $18 \mathrm{~cm}$ ) equilibrated with buffer $A$. After washing the column with $75 \mathrm{ml}$ of buffer $A$, a $350 \mathrm{ml}$ linear gradient of $0-0.5 \mathrm{M} \mathrm{NaCl}$ in the same buffer was applied. NAGK was eluted as a single peak at approximately $0.12 M \mathrm{NaCl}$. Fractions rich in enzyme were mixed, dialyzed against $20 \mathrm{~m} M$ Tris- $\mathrm{HCl} \mathrm{pH}$

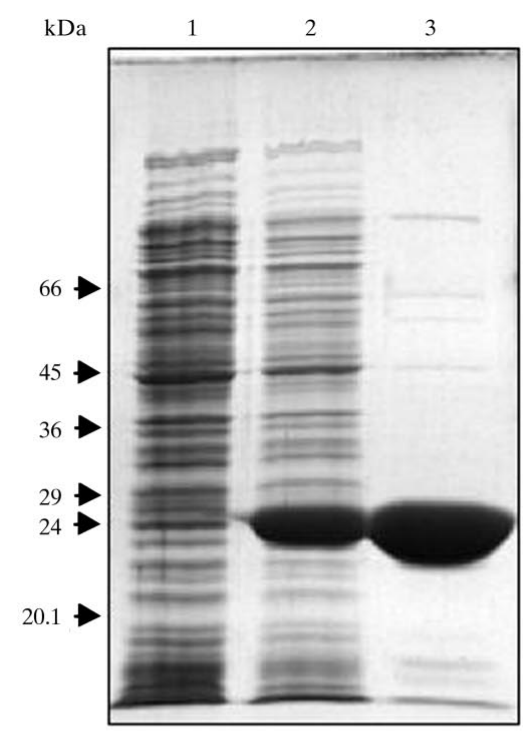

(a)

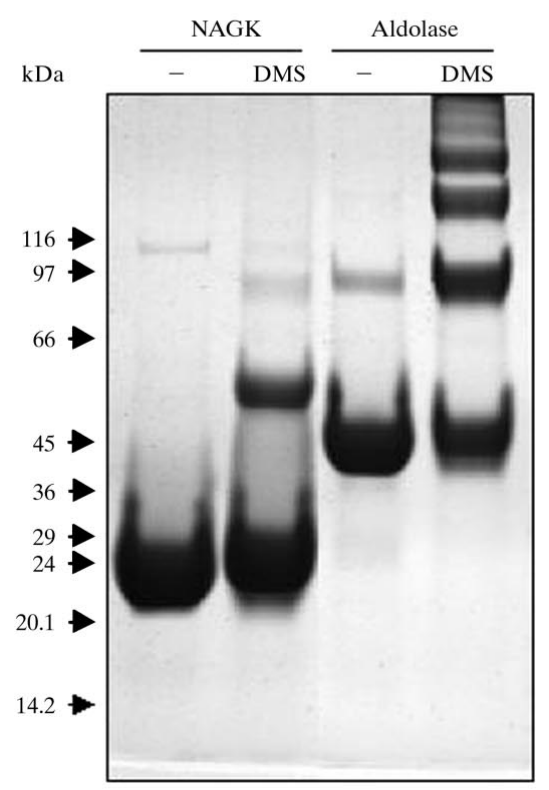

(b)

Figure 1

Expression, purification and cross-linking of NAGK. (a) SDS-PAGE of cell extracts of E. coli BL21(DE) cells transformed with plasmids pET-15b (lane 1) or pNAGK24 (lane 2). Lane 3, purified enzyme. (b) Cross-linking with dimethylsuberimidate (DMS), using the method of Davies \& Stark (1970), of $4 \mathrm{mg} \mathrm{ml}^{-1}$ NAGK or aldolase (from rabbit muscle; monomer mass $40 \mathrm{kDa}$ ). The minus sign indicates omission of DMS. Arrows mark the migration positions of protein standards of the masses indicated.
7.5, $20 \mathrm{mM} \mathrm{MgCl}_{2}, 0.2 \mathrm{~m} M$ dithioerythritol and applied to an Affigel Blue (Bio-Rad) column $(2 \times 20 \mathrm{~cm})$, which was equilibrated and washed with three column volumes of the dialysis buffer. Pure NAGK was eluted with two column volumes of this buffer supplemented with $2.5 \mathrm{~m} M$ ATP and $20 \mathrm{mM}$ NAG and was precipitated with ammonium sulfate ( $70 \%$ saturation) and stored as a slurry at $277 \mathrm{~K}$. For crystallization, the enzyme was placed in the appropriate solution by repeated centrifugal ultrafiltration (Microsep 10K, Pall Filtron).

Initial crystallization conditions using the hanging-drop vapour-diffusion method were tested with the sparse-matrix sampling procedure (Jancarik \& Kim, 1991), mixing $1.5 \mu \mathrm{l}$ of reservoir fluid and $1.5 \mu \mathrm{l}$ of $10 \mathrm{mg} \mathrm{ml}^{-1}$ NAGK in $10 \mathrm{~m} M$ sodium/ potassium phosphate $\mathrm{pH} \quad 7.0,1 \mathrm{~m} M$ dithioerythritol, either alone or supplemented with $24 \mathrm{~m} M \mathrm{NAG}, 30 \mathrm{~m} M \mathrm{MgCl}_{2}$ and $6 \mathrm{mM}$ of the inert ATP analogue AMPPNP ('substrates'). The best crystals, reaching about $0.6 \mathrm{~mm}$ in the largest dimension, were produced in about a week at $295 \mathrm{~K}$. In the absence of substrates, crys-

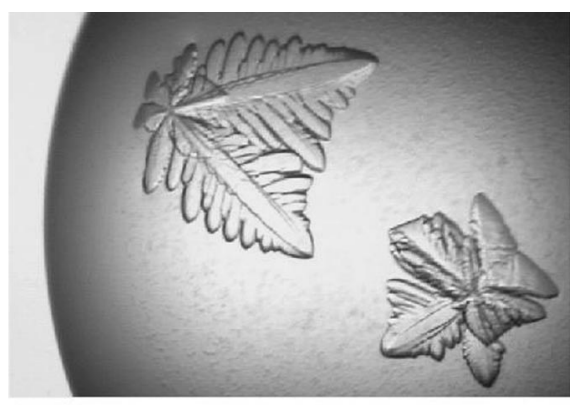

(a)

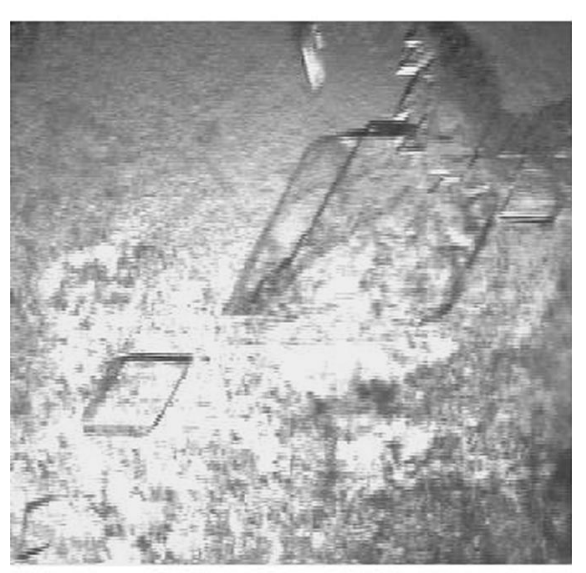

(b)

Figure 2

Typical crystals of E. coli NAGK grown at $295 \mathrm{~K}$ (a) in the absence of ligands or $(b)$ in the presence of $12 \mathrm{~m} M$ NAG, $15 \mathrm{~m} M \mathrm{MgCl}_{2}$ and $3 \mathrm{~m} M$ AMPPNP. In both cases, the largest dimension was approximately $0.6 \mathrm{~mm}$. tals were obtained with $0.1 \mathrm{M}$ sodium citrate $\mathrm{pH}$ 5.6, 26-32\% PEG 4K (Sigma) and $0.1-0.3 \mathrm{M}$ ammonium acetate; in the presence of substrates, crystals were obtained with $0.1 \mathrm{M}$ sodium acetate $\mathrm{pH} 4.6$, 27-32\% PEG monomethylether 2K (Hampton) and $0.1-0.3 \mathrm{M}$ ammonium sulfate. Harvesting solutions were $36 \%$ PEG 4K, $0.3 \mathrm{M}$ ammonium acetate and $10 \%$ ethylene glycol in $0.1 M$ sodium citrate $\mathrm{pH}$ 5.6 for crystals grown without substrates and $36 \%$ PEG monomethylether 2K, $0.24 \mathrm{M}$ ammonium sulfate and $5 \%$ ethylene glycol in sodium acetate $\mathrm{pH} 4.6$ for crystals grown with substrates. Crystals of about $0.3 \mathrm{~mm}$ in the longest dimension were examined with a MAR Research image-plate area detector mounted on a Rigaku rotating copper-anode $\mathrm{X}$-ray source operating at $40 \mathrm{kV}$ and $100 \mathrm{~mA}$. Data were collected at $100 \mathrm{~K}$ from crystals flash-cooled using an Oxford cryosystem. The data set for crystals grown with substrates was processed and scaled with $D E N Z O$ and SCALEPACK (Otwinowski, 1993), whereas for crystals grown without substrates MOSFLM (Leslie, 1990) and SCALA (Evans, 1997) were used.

NAGK activity was assayed using the method of Haas \& Leisinger (1975). One enzyme unit $\left(16.7 \times 10^{-9} \mathrm{~mol} \mathrm{~s}^{-1}\right)$ yields $1 \mu \mathrm{mol} \mathrm{min}{ }^{-1}$ hydroxamate at $310 \mathrm{~K}$. Protein was assayed using the method of Bradford (1976) with bovine serum albumin as standard. SDS-PAGE was carried out using the method of Laemmli (1970). Crosslinking with dimethyl suberimidate (DMS; Pierce) and SDS-PAGE of the covalent adducts was performed using the method of Davies \& Stark (1970).

\section{Results and discussion}

The product generated by PCR amplification of E. coli DNA was identical in size and DNA sequence to that expected from the NAGK gene (Parsot et al., 1988). Extracts of E. coli BL21(DE3) transformed with an expression plasmid (pNAGK24) which contains as an insert the amplified DNA (see $\S 2$ ), but not extracts of cells transformed with the parental vector without the insert, exhibited NAGK activity (data not shown) and showed a prominent band on SDSPAGE (Fig. 1a) migrating with the expected mass for NAGK (mass estimate from semilogarithmic plots of protein standards, $27 \mathrm{kDa}$; mass expected from the sequence, $27.15 \mathrm{kDa}$ ). The enzyme, purified in three steps from pNAGK24-transformed cells (Fig. 1a, lane 3), exhibited similar activity $\left(1.06 \mu \mathrm{mol} \mathrm{s}^{-1} \mathrm{mg}^{-1}\right.$ protein) to the purest bacterial preparation reported thus far 
(Haas \& Leisinger, 1975). Automated Edman degradation yielded the expected $\mathrm{N}$-terminal sequence (MNPLIIK), except for the lack of Met1, which is removed posttranslationally. Upon cross-linking with dimethylsuberimidate (DMS), a new band with the mass of a dimer was observed by SDS-PAGE (Fig. 1b) indicating that, as with $P$. aeruginosa NAGK (Haas \& Leisinger, 1975), E. coli NAGK forms dimers. With the tetrameric enzyme aldolase, used as a control, the four expected bands were observed (Fig. 1b; Davies \& Stark, 1970).

NAGK crystals obtained in the absence of substrates had a fronded appearance (Fig. 2a), diffracting as monocrystals to at least $2 \AA$ resolution with a conventional $\mathrm{X}$-ray source. For practical reasons, a complete data set was only collected at $2.95 \AA$ resolution $(93.4 \%$ completeness; $\left.R_{\text {merge }}=12.1\right)$. The space group was hexagonal $P 6_{1} 22$ or its enantiomorph $P 6_{5} 22$, with unit-cell parameters $a=b=78.6, c=278.0 \AA$. Packing-density considerations (Matthews, 1968) indicate that, for a monomer mass of $27 \mathrm{kDa}$, the unit cell could contain 24 monomers $\left(V_{m}=2.6 \AA^{3} \mathrm{Da}^{-1}\right.$; solvent content $53 \%$ ), corresponding to two monomers per asymmetric unit.

In the presence of substrates, crystals with a rhomboidal shape (Fig. $2 b$ ) grew from an amorphous precipitate and diffracted to at least $1.8 \AA$, although a complete data set was collected at $2.3 \AA$ ( $90.4 \%$ completeness, $\left.R_{\text {merge }}=11.5\right)$. The space group was $C 222_{1}$, with unit-cell parameters $a=60.0, b=71.9$, $c=107.4 \AA$ and an estimated eight monomers per unit cell $\left(V_{m}=2.1 \AA^{3} \mathrm{Da}^{-1}\right.$; solvent content, $42 \%$ ) or one monomer per asymmetric unit. If the molecule is organized as a dimer, then the molecular twofold symmetry axis should be coincident with a crystallographic dyad axis. In fact, crystal soaking in solutions of $\mathrm{K}_{2} \mathrm{PtCl}_{6}$ yielded a Pt derivative with a single location of the metal on the crystallographic dyad $X$ axis, suggesting that this axis could coincide with the molecular twofold axis.

Molecular replacement with the program AMoRe (Navaza, 1994) using a polyalanine model of residues $2-105$ and $160-310$ of carbamate kinase (residues 106-159 form a flexible subdomain and were omitted; Marina et al., 1999) has thus far yielded suggestive but not conclusive solutions. Further heavy-atom derivatives and the selenomethionine-substituted protein are presently being prepared.

This work was supported by grant DGES PM-97-0134-C02-01. We thank J. J. Calvete and A. Martínez for N-terminal and DNA sequencing, respectively. FG is a fellow of
Fundación Ramón Areces and SR-M and AM are pre-doctoral and post-doctoral fellows of the Generalitat Valenciana.

\section{References}

Bradford, M. M. (1976). Anal. Biochem. 72, 248254.

Cunin, R., Glansdorff, N., Piérard, A. \& Stalon, V. (1986). Microbiol. Rev. 50, 314-352.

Davies, G. E. \& Stark, G. R. (1970). Proc. Natl Acad. Sci. USA, 66, 651-656.

Evans, P. R. (1997). Jnt CCP4/ESF-EACBM Newslett. Protein Crystallogr. 33, 22-24.

Haas, D. \& Leisinger, T. (1975). Eur. J. Biochem. 52, 365-375.

Jancarik, J. \& Kim, S.-H. (1991). J. Appl. Cryst. 24, 409-411.

Laemmli, U. K. (1970). Nature (London), 227, 680-685.

Leslie, A. G. W. (1990). Crystallographic Computing. Oxford University Press.

Marina, A., Alzari, P. M., Bravo, J., Uriarte, M., Barcelona, B., Fita, I. \& Rubio, V. (1999). Protein Sci. 8, 934-940.

Marina, A., Uriarte, M., Barcelona, B., Fresquet, V., Cervera, J. \& Rubio, V. (1998). Eur. J. Biochem. 253, 280-291.

Matthews, B. W. (1968). J. Mol. Biol. 33, 491-497. Navaza, J. (1994). Acta Cryst. A50, 157-163.

Otwinowski, Z. (1993). Proceedings of the CCP4 Study Weekend. Data Collection and Processing, edited by L. Sawyer, N. Isaacs \& S. Bailey, pp. 56-62. Warrington: Daresbury Laboratory.

Parsot, C., Boyen, A., Cohen, G. N. \& Glansdorff, N. (1988). Gene, 68, 275-283. 